\title{
An Unusual Intravesical Foreign Body for Abortion Attempt. About a Case Report at Bobo Dioulasso University Teaching Hospital (Burkina Faso) and Literature Review
}

\author{
Zaré Cyprien1, Kambou Timothée ${ }^{2}$, Sanon B. Gustave1, Ouattara Adama ${ }^{2 *}$, \\ Traoré I. Alain ${ }^{3}$, Paré Abdoul Karim², Somé D. Adolphe ${ }^{4}$ \\ ${ }^{1}$ Division of General Surgery, CHU Souro Sanou, Bobo-Dioulasso, Burkina Faso \\ ${ }^{2}$ Division of Urology, CHU Souro Sanou, Bobo-Dioulasso, Burkina Faso \\ ${ }^{3}$ Division of Anesthesiology, CHU Souro Sanou, Bobo-Dioulasso, Burkina Faso \\ ${ }^{4}$ Division of Gynecology and Obstetrics, CHU Souro Sanou, Bobo-Dioulasso, Burkina Faso \\ Email: adamsouat1@hotmail.com
}

Received 24 March 2014; revised 20 April 2014; accepted 26 April 2014

Copyright (C) 2014 by authors and Scientific Research Publishing Inc.

This work is licensed under the Creative Commons Attribution International License (CC BY). http://creativecommons.org/licenses/by/4.0/

(c) (i) Open Access

\begin{abstract}
We reported a case of an intravesical foreign body in a 16 years old teenager for abortion attempt. During laparotomy for suspected pelvic appendicitis, we incidentally discovered an intravesical foreign body. From this first observation in our urology division, we reviewed the literature on the nature and circumstance of self introduction in bladder of foreign body and their surgical ablation. We emphasized the importance of endoscopy as a support of diagnosis and therapeutic of intravesical foreign body. This observation also highlighted the lack of information in our teenagers about reproductive and sexual health.
\end{abstract}

\section{Keywords}

Teenager, Abortion, Foreign Body, Intravesical, Burkina-Faso

"Corresponding author.

How to cite this paper: Cyprien, Z., et al. (2014) An Unusual Intravesical Foreign Body for Abortion Attempt about a Case Report at Bobo Dioulasso University Teaching Hospital (Burkina Faso) and Literature Review. Open Journal of Urology, 4, 33-36. http://dx.doi.org/10.4236/oju.2014.44006 


\section{Introduction}

The direct self introduction of a foreign body in the bladder realized during an attempt of clandestine abortion is an exceptional fact, reported in the literature through some publications. From a case of auto-introduction of foreign body in vagina during an attempt of abortion, which accidentally passed through the urethra then into the bladder, we reviewed the difficulties of diagnosis in such a clinical presentation, and we had to mime acute pelvic appendicitis. The place of endoscopy both in diagnostic and therapeutic purpose is discussed. Nature of the foreign body and circumstances of introduction are discussed through a review of the literature.

\section{Observation}

S. R., 16 years old female teenager, was admitted in the emergency room of the surgical department of Souro Sanou University Teaching Hospital of Bobo-Dioulasso, Burkina Faso. She was received on 7th June 2013 for burning micturition, complain of intense pain of suprapubic region and gross hematuria lasting for 4 days. Interrogation found a sudden onset of hematuria accompanied by burning micturition, the history of unprotected sexual intercourse 3 months ago. The patient did not have any history of surgery or any endourological procedure before her admission, no history of amenorrhea and no family history suggestive of mental health problems. Physical examination noted a painful and tender suprapubic region. The gynecological examination was normal except a thickness of the anterior vaginal wall. There was also a pain in the anterior wall of the vagina. The immunological pregnancy test (TIG) was negative. The diagnosis of acute cystitis or bladder stones was suspected. The patient was hospitalized in urology unit for complementary investigations. The serum creatinine and urea were normal (creatinine $59 \mathrm{mmol} / \mathrm{L}$, urea $<3 \mathrm{mmol} / \mathrm{L}$ ). The blood count (BC) performed revealed a moderate anemia and leukocytosis. The Urinalysis, the Addis account and ultrasound assessment requested could not be carried out urgently. The third day of hospitalization, despite antibiotic administration (ciprofloxacin) and anti-inflammatory, evolution has been marked by the exacerbation of pain sensation with a pelvic mass, firm and tenderness. With such clinical presentation, we have suspected a pelvic acute appendicitis and an exploratory laparotomy was performed. A midline laparotomy under umbilical has noted an appendix in pelvic position with normal appearance macroscopically, uterus was not gravid and adnexa were normal. Bladder presented an intravesical foreign body sensation; there is a strange structure in a bladder (Figure 1). Cystotomy was used to extract the foreign body (Figure 2). This was a rubber pipe of petrol of a motorcycle, $18 \mathrm{~mm}$ in diameter and about $20 \mathrm{~cm}$ length (Figure 3). Bladder inspection did not reveal any abnormalities. On further discussion with the patient on the fifth postoperative day in search of the circumstances of introduction of this unusual object in the bladder, she admitted inserting this device into the vagina for abortion attempt to prevent the risk of pregnancy due to unprotected sexual intercourse three months ago. The postoperative course was uneventful and the patient was discharged on the tenth postoperative day after removal of the urethrovesical catheter.

\section{Discussion}

The discovery of intravesical foreign body is not an exceptional fact in medical practice but it remains a very unusual, arousing curiosity and the problem of its introduction mode. The circumstances of such a medical curiosity are variants, ranging from voluntary self introduction for the purpose of sexual stimulation or abortion to

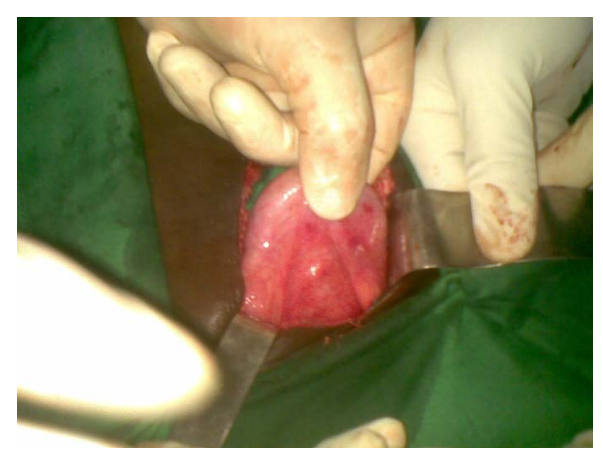

Figure 1. Foreign body in the bladder grasped between fingers. 


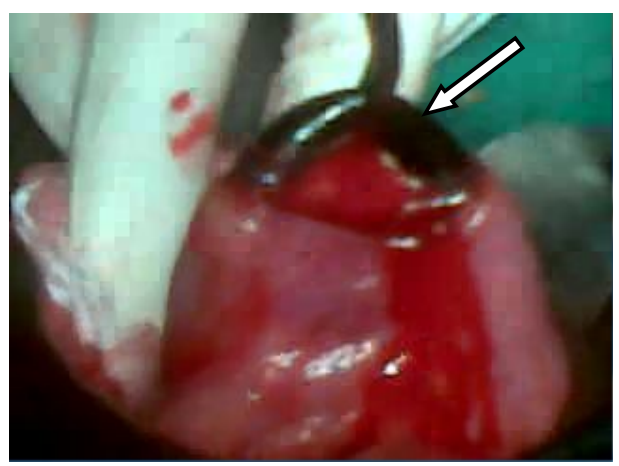

Figure 2. Removal of the rubber fuel line of motorcycle (arrow) during cystotomy.

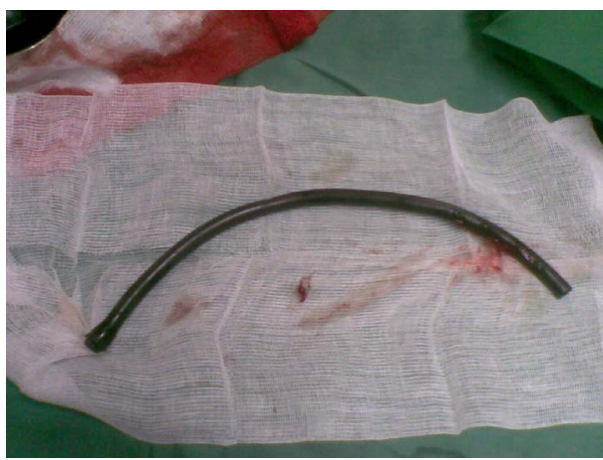

Figure 3. The rubber fuel line of motorcycle $(20 \mathrm{~cm} \times 1.8 \mathrm{~cm})$.

accidental or iatrogenic introduction as evidenced by numerous publications [1]-[5]. The presence of a foreign body in the bladder during an abortive attempt might think of a trans-uterovesical migration by uterine perforation and not a direct introduction. In our case, it was a direct introduction trans-urethrovesical confirmed by the absence of vesico-uterine or vesico-vaginal communication intraoperatively. It was probably an inadvertently direct introduction, the teenager wanting to introduce the rubber tube instead of the uterus via the vagina in the urethra. The shortness of female urethra and especially the teenager ignorance of the anatomy could be the root cause of the direct and total introduction of a foreign body in the bladder. This highlights teenagers' lack of education and information on sexual health as sex remains taboo in our societies. Unwanted pregnancies are the reason for clandestine abortion among youth and adolescents [6]. For some African authors, the mechanical method is mostly used in clandestine practice of abortion [5]-[6]. The medical literature is well supplied with publications on intravesical foreign body. Thus Osca and colleagues reported eight cases of self-inserted foreign bodies in the lower urinary tract treated from 1976 to 1990, of which five were intravesical. Objects found include electric cable, tweezers, a hair pin, a drawing pin, pebbles, and a paper clip [7]. Recently in Nigeria, Irekpita and colleagues have reported a case of electric wire, as foreign body in bladder [8]. Clinical manifestations of intravesical foreign bodies are not specific and include a set of signs such as cystalgia, pollakiuria, urgenturia, hematuria, dysuria and acute urinary retention [1]-[2]. The clinical presentation in our patient as a febrile pelvic pain syndrome with irritative urinary symptoms mimicking acute appendicitis has misled the diagnosis. Indeed the context of hemorrhagic cystitis, pelvic pain and fever without notion of abortion maneuvers reported by the patient, we were away from the diagnosis. In our context of lack of morphological and endoscopic examinations, the diagnosis of acute appendicitis was suspected and a laparotomy was indicated. Usually the foreign body can be detected by plain abdominal radiography of the kidney, ureters and bladder (KUB), the ultrasonography of the urinary tract and urethrocystoscopy which is the essential test that says diagnosis and precise location and nature of the foreign body [2]. The introduction of intravesical foreign body in an abortive aim has also been reported. Fear of an unwanted pregnancy that motivated our patient to use such a maneuver calls for the need to provide adolescent sexual and reproductive healthcare to teenagers. Intravesical foreign bodies of various kinds have 
been described in the literature [1]-[3] [5] [8]. The following bodies were reported: electric battery, pencil, pearl, bulb, wire, carrot, toy [1]. In this observation, it is a rubber tube, fuel line of motorcycle, measured 18mm in diameter and $20 \mathrm{~cm}$ in length. Foreign bodies in the bladder migrating from neighboring anatomical structures are also different. It could be an intrauterine device (IUD) [2]-[3], an artificial urinary sphincter or osteosynthesis material [1]. We can also find in the bladder a gauze or stones formed from a non-absorbable suture attached to the bladder wall [3]. A cystoscopy could have allowed us to promptly make the diagnosis and to make its eventual removal. Endoscopy is nowadays the method for the extraction of intrabladder foreign bodies according to several authors [3] [9]-[10]. Unfortunately in our case, not having these mini-invasive techniques, we performed a cystotomy to remove the foreign body. However, the foreign body ablation method should take into account the nature, size, location, mobility of the foreign body as well as the patient's age and means available [3] [9] [11].

\section{Conclusion}

Clandestine abortion is a rare cause of accidental introduction of a foreign body in the bladder, often difficult to diagnose in the context lack of endoscopic equipment or ultrasound assessment in emergency. It is important to perform endoscopy in presence of persistent or unexplained urinary tract symptoms and to promote sexual and reproductive health among teenagers and encourage the dissemination of contraceptive methods among them for preventing unwanted pregnancies, source of illegal abortion.

\section{References}

[1] Potretzke, A.M., Wong, K.S. and Downs, T.M. (2013) Intravesical Foreign Body via a Vesicoperineal Fistula. Case Reports in Urology, 2013, Article ID: 659582. http://dx.doi.org/10.1155/2013/659582

[2] Elhams, A., Kabbaj, M., Karmouni, T., Tazi, K., Elkhader, K., Koutani, A., et al. (2007) Corps étranger de vessie (à propos de 4 cas). African Journal of Urology, 13, 226-230.

[3] Rafique, M. (2008) Intravesical Foreign Bodies: Review and Current Management Strategies. The Journal of Urology, 5, 223-231.

[4] Moon, S.J., Kim, D.H., Chung, J.H., et al. (2010) Unusual Foreign Bodies in the Urinary Bladder and Urethra Due to Auto Erotism. International Neurourology Journal, 14,186-189. http://dx.doi.org/10.5213/inj.2010.14.3.186

[5] Oguntayo, O.A, Zayyan, M., Odogwu, K., Koledade, K., Mbibu, H., Bello, A. and Sani, S. (2009) Foreign Body (Metallic Flashlight Cover) in the Urinary Bladder Mimicking Advanced Cancer of the Cervix: Case Report and Review of the Literature. African Journal of Urology, 15, 111-113. http://dx.doi.org/10.1007/s12301-009-0018-3

[6] Sepou, A., Ngbale, R., Yanza, M.C., Domande-Modanga, Z. and Nguembi, E. (2004) Analysis of Abortions at a Community Maternity Hospital in Bangui. Medecine Tropicale, 64, 61-65.

[7] Osca, J.M., Broseta, E., Server, G., et al. (1991) Unsual Foreign Bodies in the Urethra and Bladder. British Journal of Urology, 68, 510-512. http://dx.doi.org/10.1111/j.1464-410X.1991.tb15395.X

[8] Irekpita, E., Imomoh, P., Kesieme, E. and Onuora, V. (2011) Intravesical Foreign Bodies: A Case Report and a Review of the Literature. Journal of Medical Case Reports Journal, 4, 35-39.

[9] Van Ophoven, A. and Dekernion, J.B. (2000) Clinical Management of Foreign Bodies of the Genitourinary Tract. The Journal of Urology, 164, 274-287. http://dx.doi.org/10.1016/S0022-5347(05)67342-9

[10] Rahman, N.U., Elliott, S.P. and McAninch, J.W. (2004) Self-Inflicted Male Urethral Foreign Body Insertion: Endoscopic Management and Complications. BJU International, 94, 1051-1053. http://dx.doi.org/10.1111/j.1464-410X.2004.05103.x

[11] Aliabadi, H., Cass, A.S., Gleich, P. and Johnson, C.F. (1985) Self Inflicted Foreign Bodies Involving Lower Urinary Tract and Male Genitals. The Journal of Urology, 26, 12-16.

\section{Abbreviations}

CHU Bobo-Dioulasso: University Teaching Hospital of Bobo-Dioulasso

TIG: Immunological Pregnancy Test

BC: Blood count

IUD: Intrauterine Device

KUB: Kidney Ureters and Bladder 